\title{
Capsule Commentary on Gryczynski et al., Validation of the TAPS-1: A Four-Item Screening Tool to Identify Unhealthy Substance Use in Primary Care
}

\author{
Sarah M. Hartz, MD PhD \\ Department of Psychiatry, Washington University School of Medicine in St. Louis, St. Louis, MO, USA.
}

J Gen Intern Med 32(9):1026

DOI: $10.1007 / \mathrm{s} 11606-017-4119-6$

(c) Society of General Internal Medicine 2017

$\mathrm{T}$ here is a huge gap between the need for and the receipt of treatment for substance use disorder: although 20.2 million Americans were estimated to have had an alcohol or drug use disorder within the past year, only $12 \%$ of those individuals received treatment during that period. ${ }^{1}$ Primary care clinics represent an opportunity to identify individuals in need of treatment.

$\mathrm{Wu}$ and colleagues recently conducted a clinical trial to evaluate primary care screening for substance misuse with the TAPS tool, the National Drug Abuse Treatment Clinical Trials Network's tobacco, alcohol, prescription medications, and substance use/misuse screen and brief assessment tool. ${ }^{2}$ This two-stage assessment tool was shown to be both sensitive and specific for identifying problem substance use and differentiating between misuse of illicit substances and misuse of prescription medications. ${ }^{3}$ However, one limitation of the twostage tool is that follow-up questions can complicate what needs to be a simple screener for busy primary care clinics.

This study by Gryczynski and colleagues ${ }^{4}$ extracted the nine-item screening portion of the TAPS tool (TAPS-1), and evaluated the efficacy of this instrument alone in identifying individuals with substance misuse and substance use disorder. The authors identified optimal cutpoints for reliable identification of tobacco use disorder, alcohol use disorder, misuse of illicit substances, and misuse of prescription drugs. Of note, although participants were recruited from primary care clinics, they participated anonymously. It is possible that participants would respond differently if they knew that the results were to be discussed with their physician and/or entered into the medical record.

For clinicians and administrator, this study provides a validated nine-item screening tool for identifying individuals with substance misuse or substance use disorder, easily given as a waiting room questionnaire. This gives primary care providers the opportunity to optimize clinical management in an underserved population.

Corresponding Author: Sarah M. Hartz, MD PhD; Department of PsychiatryWashington University School of Medicine in St. Louis, St. Louis, MO, USA (e-mail: hartzs@wustl.edu).

\section{Compliance with Ethical Standards:}

Conflict of Interest: The author has no conflicts of interest with this article.

\section{REFERENCES}

1. Center for Behavioral Health Statistics and Quality. 2014 National Survey on Drug Use and Health: Detailed Tables. Rockville, MD: Substance Abuse and Mental Health Services Administration (SAMHSA); 2015.

2. Wu LT, McNeely J, Subramaniam GA, Sharma G, VanVeldhuisen P, Schwartz RP. Design of the NIDA clinical trials network validation study of tobacco, alcohol, prescription medications, and substance use/misuse (TAPS) tool. Contemp Clin Trials. 2016;50:90-97.

3. McNeely J, Wu LT, Subramaniam G, Sharma G, Cathers LA, Svikis D, et al. Performance of the Tobacco, Alcohol, Prescription Medication, and Other Substance Use (TAPS) Tool for Substance Use Screening in Primary Care Patients. Ann Intern Med. 2016;165:690-699.

4. Gryczynski J, McNeely J, Wu LT, Subramaniam GA, Svikis DS, Cathers LA, Mitchell SG, O'Grady KE, Schwartz RP. Validation of the TAPS-1: A Four-Item Screening Tool to Identify Unhealthy Substance Use in Primary Care. J Gen Intern Med. 2017; doi:10.1007/s11606-017-4079-x. 